\title{
Are the benefits of lean rapid process improvement workshops in healthcare worth the investment?
}

\author{
James G. Chan ${ }^{1}$, Jalil Safaei*2, ${ }^{2}$ Thomas Rotter ${ }^{3}$ \\ ${ }^{1}$ School of Health Sciences, University of Northern British Columbia, Prince George, BC., Canada \\ ${ }^{2}$ Department of Economics, University of Northern British Columbia, Prince George, BC., Canada \\ ${ }^{3}$ Health Quality Programs, Queen's University, Kingston, Ontario, Canada
}

Received: January 19, 2020

DOI: $10.5430 /$ jha.v9n2p1
Accepted: March 24, 2020

Online Published: April 9, 2020

\begin{abstract}
Background: Many organizations have adopted Lean tools to improve healthcare, but few studies adequately evaluate the effectiveness of Lean tools, such as Rapid Process Improvement Workshops (RPIWs).

Objective: To evaluate the effectiveness of RPIWs conducted in surgical services at two hospital sites from economic and statistical perspectives.

Methods: Retrospective data over three years from the two interventions sites were used for a cost-benefit analysis in the form of Return on Investment (ROI). The Interrupted Time Series (ITS) method was used to analyze the trends of selected process measures such as surgical volumes, overtime, and sick time hours during intervention and post-intervention periods at the two sites. Also, comparable data from two control sites were used to statistically compare the trends of some of the process measures between the intervention and control sites.

Results: The cumulative effects of the six RPIWs performed at each site were examined. The results did not produce any evidence to indicate that the outcomes justify the investments. The ITS analysis revealed no indication of systematic and sustained change in the pattern of process measures at the intervention sites as a result of RPIWs. Nor did they provide significant or conclusive evidence when comparing the process measures between the intervention and control sites.

Conclusions: This study identifies some of the difficulties of empirically calculating the ROI of RPIWs, and provides evidence that any realized benefits due to RPIWs implemented in two hospitals were not worth the investment. Such a result may lead us to challenge any unfounded claims of high monetary benefits from Lean tools or similar quality improvement initiatives.
\end{abstract}

Key Words: Lean, Economic evaluation, Return on Investment, Statistical analysis, Interrupted Time Series, Surgical services

\section{INTRODUCTION}

Over the last several decades, Lean has been adopted by industries the world over as a method to reduce error, eliminate waste, and improve productivity with cost savings featured as one of the ultimate outcomes. ${ }^{[1]}$ From its origins in the automotive manufacturing industry, ${ }^{[2]}$ Lean has since been adopted by many healthcare organizations to varying degrees. ${ }^{[3]}$ Research on Lean in healthcare has also proliferated ${ }^{[4]}$ although the majority of studies offer anecdotal accounts of Lean's success ${ }^{[5]}$ and relatively few thoroughly examine any associated benefits and outcomes. ${ }^{[6,7]}$

One of the difficulties with research in this area is the fact that there are multiple interpretations of what constitutes Lean, which gives rise to many approaches to implementa-

\footnotetext{
*Correspondence: Jalil Safaei; Email: Jalil.Safaei@unbc.ca; Address: Department of Economics, UNBC. 3333 University Way, Prince George, BC. V2N-4Z9, Canada.
} 
tion. ${ }^{[8,9]}$ In spite of the criticism that Lean is ill-defined, ${ }^{[10]}$ there is recent progress in terms of developing an operational definition of Lean, which in turn, could usher advancements of research in this area. ${ }^{[11]}$ Of particular importance is the need to specifically define the Lean tools under investigation in order to enable a better understanding of the causal relationships between interventions and outcomes and to allow for meaningful comparisons across studies. ${ }^{[8]}$

One key tool used in Lean is the Kaizen event, also known as a Rapid Process Improvement Workshop (RPIW). ${ }^{[12,13]}$ Kaizen is a Japanese term that translates to "change for the better", ${ }^{[14]}$ and a Kaizen event/RPIW typically convenes a broad range of stakeholders for approximately one week of intense improvement effort whereby people work together to identify waste, remove or eliminate it, and improve processes using a variety of Lean tools and activities. Improvements achieved during the RPIW can be monitored via audits at 30 , 60 , and 90 days post-RPIW and recorded as indications of sustainability and success. ${ }^{[15]}$

There have been many studies of Lean in healthcare that report positive outcomes. However, there are far fewer studies that critically evaluate Lean, either at the individual project level or at the systemic level. ${ }^{[16,17]}$ Some studies report large financial gains resulting from Lean tools and activities. Within the surgical services sector, for example, one study reported $\$ 34,678$ savings per esophagectomy patient following their Kaizen events. ${ }^{[18]}$ Another study estimated opportunity revenue of \$330,000 annually from improved operating room turn-over times due to Lean interventions. ${ }^{[19]}$ In a further study of an RPIW undertaken to optimize on-time performance in two operating rooms, the authors attributed an annualized benefit of $\$ 72,696$ to the Lean intervention. ${ }^{[20]}$ Lastly, Schwarz et al. ${ }^{[21]}$ estimated a cost savings of $€ 366,000$ annually if operating room capacity could be fully optimized based on their study of Lean events.

In spite of these promising reports of positive financial gains, research in this field is often plagued by methodological limitations such as a lack of statistical analyses, selection bias, failure to include comparison groups, and other confounding factors. Most economic studies can be criticized for not clearly describing the type of Lean intervention or omitting costing from the analysis.

In a recent study that attempts to reduce hospital associated infections in surgery departments, the authors adequately describe the Lean improvements and claim a significant reduction in the average length of stay (from 45 days to 36 days) along with concomitant cost savings for hospitals. ${ }^{\text {[22] }}$ Unfortunately, there is insufficient evidence of sustainability of the improvements and a dearth of information related to economic analysis. Improta, Balato, Romano et al. ${ }^{[23]}$ also report a significant reduction of length of stay in their analysis of Lean methods applied to the management of prosthetic hip replacement surgery. These authors estimate an annual cost savings of $€ 260,000$, but the costs associated with the Lean interventions are not reported and the economic analysis is not appropriately demonstrated.

One study that thoroughly describes the interventions and accounted for the cost of Lean implementation reported a $36 \%$ reduction in length of stay, and estimated \$1 Million in annual return on investment. ${ }^{[24]}$ Still, the study lacked a control group, did not monitor or report on gains beyond one year (in order to show that the benefits were truly sustained), and hired an additional surgeon to increase surgical performance at their facility.

The shortcomings of research in this area challenges academics and practitioners to more critically evaluate Lean tools and activities. Indeed, Lean seems to permit the clear identification of waste and the calculation of potential savings perhaps more than other quality improvement methods. ${ }^{[16]}$ In this study, we aimed to systematically evaluate six RPIWs conducted within surgical services at two hospitals along with two respective control hospitals from both economic and statistical perspectives. A key research question was, "What are the economic benefits of Lean RPIWs?" A second, but equally important question was, "Are the improvements associated with Lean RPIWs sustained?" These questions are of interest to health services researchers in terms of methodology, to healthcare leaders who are considering Lean implementations, and to Lean practitioners/healthcare staff who must be selective in their efforts to justify the value of their interventions.

\section{METHODS}

\subsection{Context}

This research was conducted at a large healthcare system in British Columbia, Canada (henceforth referred to as the Health System). All components of the study were conducted in accordance with Research Ethics Board approval (E2015.0112.003.02) and the Second Edition of the TriCouncil Policy Statement: Ethical Conduct for Research Involving Humans. ${ }^{[25]}$ The Tri-Council Policy Statement is a joint policy of Canada's three federal research agencies to promote the ethical conduct of research involving humans. Given that this study utilized de-identified systems-level data that is routinely collected in surgical services, patient consent to review their medical records was not required by the Research Ethics Board.

Like in many Health Systems, long wait times for elective 
surgery was an issue in this context, which prompted improvement interventions. Thus, a series of six RPIWs were undertaken at two different hospitals (herein identified as Site 1 and Site 2) between December 2013 and December 2014. Site 1 is a large tertiary facility with a total of 400 beds. This site is a teaching hospital that receives referrals from across the health system. Site 2 is a regional hospital with a total of 140 beds, and offers a full gamut of services, including inpatient, surgical, and emergency services.

The RPIWs investigated in this study have several core elements in every application: formal sponsorship by senior healthcare leaders and support from internal Lean consultants; eight weeks of pre-planning preceding each five-day RPIW; Project Forms that outline the RPIWs; staff training in Lean; Lean assessment activities (eg, value stream mapping, process flow charting); improvement idea generation; systematic improvement trials using Lean tools, techniques, and methods; measurement reports of improvement; and public reporting/presentation at the conclusion of the RPIW.

The following is a brief description of the series of six RPIWs conducted at Site 1:

- RPIW\#1 (December 9-13, 2013) was designed to address problems related to the flow of implants in the operating room.

- RPIW\#2 (February 17-21, 2014) addressed identifying, re-ordering, repairing, and re-assembling broken/un-usable/missing surgical instruments.

- RPIW\#3 (May 24-28, 2014) targeted operating room change-over time.

- RPIW\#4 (April 28-May 2, 2014) focused on the ontime performance of the first case each day.

- RPIW\#5 (May 26-30, 2014) examined processes upon the patient's arrival at the hospital on the day of surgery.

- RPIW\#6 (June 23-27, 2014) concentrated on presurgical screening processes.

The RPIWs conducted at Site 2 were designed to address the unique needs of the surgical department at this facility:

- RPIW\#1 (December 9-13, 2013) examined the flow of information within the pre-surgical screening office.

- RPIW\#2 (February 17-21, 2014) focussed on the flow of information and patients through the day-surgery department.

- RPIW\#3 (March 24-28, 2014) targeted the flow of emergency surgical patients and the overall operations of the surgery department.
- RPIW\#4 (April 28-May 2, 2014) attempted to optimize the preparation of the operating room schedule.

- RPIW\#5 (May 26-30, 2014) intended to build on RPIW\#3 and further improve patient flow for individuals requiring emergency surgery.

- RPIW\#6 (October 20-24, 2014) addressed complications associated with wound care.

The approach to conducting RPIWs in this health system was very rigorous, using standardized components that have been developed by leading health systems. ${ }^{[15]}$ Full descriptions of each RPIW are available from the authors.

\subsection{The technical approaches of the study}

The study consists of two types of analyses. One is economic analysis in the form of the calculation of the Return on Investment (ROI) rates at the intervention sites, where the RPIWs have been implemented. As part of the investigation of the cumulative effect of the RPIWs, statistical analyses were also performed to examine process measures before and after the RPIW interventions at Sites 1 and 2, and in comparison to control sites (Sites 3 and 4, respectively). The two types of analyses are described below.

\subsubsection{Economic analysis}

The specific conceptual framework underlying our economic analysis or evaluation is the framework provided by Drummond, Sculpher, Torrance, O'Brien, and Stoddart. ${ }^{[26]}$ The ROI analysis was performed for the cumulative effects of all RPIWs for each site. The study was retrospective in nature, and the data was extracted from data warehouses that store routinely collected data.

RPIW costs. The process for obtaining costing data and calculating costs associated with the RPIWs in this study is similar to the meticulous costing analysis used by Sari, Rotter, Goodridge, Harrison, and Kinsman. ${ }^{[27]}$ For instance, exact wage rates for each RPIW participant (and compensation backfill) were tallied along with the estimates of employment benefits. To complete the elements required for the ROI formula, the total costs of the RPIWs were tallied for both Site 1 and Site 2.

Some indirect costs were not included in the costing calculations because they proved too difficult to quantify (eg, use of meeting rooms), or because the costs were considered to be part of daily operations (eg, post-RPIW staff time related to implementing improvements and updating measurement reports). Costs associated with originally introducing Lean to the organization (such as training costs, materials, etc.) were also not included, since the Lean program was established long before this research was initiated. While other authors 
have omitted start-up costs in this sort of analysis, the net cost savings may be overstated without accounting for these factors. ${ }^{[28]}$ Costing details for the RPIWs are available from the authors.

RPIW benefits. To measure the cumulative effect of the six RPIWs performed at each site, three process measures were identified as quantifiable outcomes to be used for calculating the ROI: (1) surgical volumes, (2) overtime utilization, and (3) sick time utilization. The rationale for selecting these measures is as follows; if Lean is effective in removing waste and improving efficiency, then we can expect to see improvement in any or all of these areas. For example, if we assume a causal relationship between the RPIW interventions and increased surgical volumes - and no resources added to the service area-then the RPIWs could lower the cost per surgery, resulting in cost reduction. If the monetized benefit from lowered surgical costs exceeds the investment in the RPIWs, a positive ROI could be realized. This outcome would reflect an ROI in actual dollars resulting from the RPIWs, and not some hypothesized future cost avoidance as often reported in the literature. ${ }^{[29]}$ This approach to measuring RPIW benefits is consistent with the approach to cost reduction through waste elimination as described by Kaplan and Boyer. ${ }^{[30]}$ Following this line of reasoning, increased surgical volumes would also impact wait times for elective surgery, which was a major driver for undertaking improvement efforts in the Health System.

Similarly, if the RPIWs resulted in more efficient management of surgical services, we could expect a reduction in overtime utilization. ${ }^{[31]}$ Lastly, if the RPIWs improved staff experience and increased staff engagement through smoother operations, we may expect to observe reductions in sick time utilization. ${ }^{[32]}$

Calculation of ROI. An overall ROI calculation was performed to examine the cumulative effect of all RPIWs at Site 1 and Site 2. This analysis attempts to quantify any benefits/cost savings resulting from the RPIWs in terms of surgical volumes, overtime, and sick time utilization. In this study, monetized benefits are expressed as cost savings resulting from lower costs of surgery, overtime, or sick time. Any monetized cost savings were compared to the costs of conducting the RPIWs in order to determine whether the benefits/cost savings exceeded the investments at each site.

To determine benefits/cost savings resulting from improvements to surgical volumes, an average cost per case was used. Estimates of the average cost per surgical case were calculated from internal administrative data. The actual costs associated with staff overtime and sick time were also used in the ROI analysis. Overtime and sick time utilization data included in this study represent all staff in the Operating Room Departments excluding physicians/surgeons.

Three distinct time periods were defined for analysis in this study: the period before the RPIWs were introduced (ie, the pre-intervention period spanning December 2012 to December 2013), the period during which the RPIWs were conducted (ie, the intervention period spanning December 2013 to December 2014), and the post-intervention period (December 2014 to December 2015). Only surgeries performed during regular operating room hours were included; surgeries performed during evenings, weekends, holidays, and emergent cases were excluded from the analysis. The underlying hypothesis was that the average number of surgeries performed at Site 1 and Site 2 would remain the same and not systematically change following the RPIWs. However, if efficiency gains resulting from the RPIWs permitted more surgeries within normal operating hours, then cost savings would be realized due to reduced costs per case.

\subsubsection{Statistical analysis}

To go beyond the deterministic ROI analysis, additional analyses were conducted to statistically examine any observed improvements in the process measures following the RPIWs. The Interrupted Time Series (ITS) method was used to check whether there had been any changes or interruptions in both the level and slope of the process measures time series. The ITS method uses the detailed information and disaggregated data to examine any breaks in the structure of data. It is a very reliable method for evaluating the effects of interventions on health outcomes at the population level, especially when time series data points are large enough, which is the case in this study. ${ }^{[33-37]}$

The process measures were analyzed at the two intervention hospitals (Site 1 and Site 2). They were also compared between the intervention hospitals and their matched (control) hospitals in the same Health System (Site 3 and 4, respectively). The control sites were selected according to prespecified organizational characteristics, such as number of funded beds, types and volumes of procedures performed, and the catchment areas served.

For the ITS analyses, a baseline linear model was fitted to the data to estimate the initial level (intercept) and the slope (gradient) in the process measures time series as follows (see Equation 1):

$$
Y_{t}=C+B t+u_{t}
$$

where $Y_{t}$ is the process measure variable, $C$ is the intercept, $B$ is the slope, and $u_{t}$ is a random error. 
The baseline model was then modified to allow for changes or interruptions in the intercept as well as slope of the fitted trend line during the intervention and the post-intervention periods for capturing the effects of the intervention, if any, as follows (see Equation 2):

$$
Y_{t}=\left(C+C_{1}+C_{2}\right)+\left(B+B_{1}+B_{2}\right) t+u_{t}
$$

In this case, $C_{1}$ and $C_{2}$ represent the changes in the levels of the process measure series $\left(Y_{t}\right)$ during the intervention and post-intervention periods, respectively. $B_{1}$ and $B_{2}$ denote the changes in the slopes of $Y_{t}$ for the two periods in the same order. The estimated values of $C_{1}, C_{2}, B_{1}$ and $B_{2}$ are used to measure the magnitudes of potential interruptions as a result of intervention, and whether such interruptions or changes are statistically significant. Positive values for $C_{1}, C_{2}, B_{1}$ and $B_{2}$ imply improved efficiency in surgical performance, but decreased efficiency in sick time and overtime hours.

Table 1. Monitized results of the RPIWs

\begin{tabular}{|c|c|c|c|c|c|c|}
\hline \multicolumn{7}{|c|}{ Pre-Intervention to Intervention Period } \\
\hline Site & Performance Metric & $\begin{array}{l}\text { Pre-Intervention Period } \\
\text { (Dec } 2012 \text { to Dec 2013) }\end{array}$ & $\begin{array}{c}\text { Intervention Period } \\
\text { (Dec } 2013 \text { to Dec 2014) }\end{array}$ & $\begin{array}{c}\text { Unit } \\
\text { Difference }\end{array}$ & Cost Savings" & $\begin{array}{l}\text { Total RPIW } \\
\text { Costs }\end{array}$ \\
\hline \multirow[t]{4}{*}{1} & Number of Surgeries & 10,109 & 10,162 & $\uparrow 53$ & $\$ 89,358$ & \\
\hline & End of Shift Overtime & 4,150 & 3,607 & $\downarrow 543$ & $\$ 22,629$ & \\
\hline & Sick Time & 9,952 & 9,239 & $\downarrow 713$ & $\$ 8,755$ & \\
\hline & Site 1 Total & & & & $\$ 120,742$ & $\$ 143,287$ \\
\hline \multirow[t]{4}{*}{2} & Number of Surgeries & 4,607 & 4,548 & $\downarrow 59$ & $-\$ 61,006$ & \\
\hline & End of Shift Overtime & 722 & 892 & $\uparrow 170$ & $-\$ 7,975$ & \\
\hline & Sick Time & 1,441 & 636 & $\downarrow 805$ & $\$ 34,263$ & \\
\hline & Site 2 Total & & & & $-\$ 34,718$ & $\$ 146,954$ \\
\hline \multicolumn{7}{|c|}{ Pre-Intervention to Post-Intervention Period } \\
\hline Site & Performance Metric & $\begin{array}{l}\text { Pre-Intervention Period } \\
\text { (Dec } 2012 \text { to Dec 2013) }\end{array}$ & $\begin{array}{l}\text { Post-Intervention Period } \\
\text { (Dec } 2014 \text { to Dec 2015) }\end{array}$ & $\begin{array}{c}\text { Unit } \\
\text { Difference }\end{array}$ & Cost Savings" & $\begin{array}{l}\text { Total RPIW } \\
\text { Costs }\end{array}$ \\
\hline \multirow[t]{4}{*}{1} & Number of Surgeries & 10,109 & 9,962 & $\downarrow 147$ & $-\$ 259,161$ & \\
\hline & End of Shift Overtime & 4,150 & 3,410 & $\downarrow 740$ & $\$ 41,297$ & \\
\hline & Sick Time & 9,952 & 10,249 & $\uparrow 297$ & $-\$ 18,007$ & \\
\hline & Site 1 Total & & & & $-\$ 235,871$ & $\$ 143,287$ \\
\hline \multirow[t]{4}{*}{2} & Number of Surgeries & 4,607 & 4,674 & $\uparrow 67$ & $\$ 69,211$ & \\
\hline & End of Shift Overtime & 722 & 923 & $\uparrow 201$ & $-\$ 12,914$ & \\
\hline & Sick Time & 1,441 & 1,276 & $\downarrow 165$ & $\$ 16,059$ & \\
\hline & Site 2 Total & & & & $\$ 72,356$ & $\$ 146,954$ \\
\hline
\end{tabular}

Note. ${ }^{*}$ Cost savings if: increase in surgeries, decrease in overtime, or decrease in sick time. Cost increases are reported as negative values.

\section{RESUlts}

\subsection{Results of ROI analyses}

Table 1 contains the data used to calculate the ROI of RPIWs conducted at the two intervention sites. The initial ROI analysis was conducted between the pre-intervention and intervention periods. Since most of the RPIWs were complete half way through the intervention period, it was felt that sufficient time had elapsed within the intervention year for improvements to stabilize and yield results (if, in fact, they were effective and successfully sustained).

The upper portion of Table 1 shows that there were 10,109 surgeries performed in the pre-intervention period as compared to 10,162 surgeries in the intervention period at Site 1 , an increase of 53 surgeries performed in the intervention period. An average cost per case was used to calculate dollar figures associated with the volume variability between the pre-intervention period and the intervention period for each site. The estimated average cost per case at Site 1 was $\$ 1,686$, 
so the resultant net gain was $\$ 89,358$.

For overtime, there were 4,150 hours logged in the preintervention period versus 3,607 hours in the intervention period, for a reduction of 543 hours and a cost saving of $\$ 22,629$. Sick time also decreased, from 9,952 hours in the pre-intervention period to 9,239 hours in the intervention period; with this difference of 713 hours, there was a cost saving of $\$ 8,755$.

The costs of conducting the six RPIWs at Site 1 was $\$ 143,287$, while cost savings totalled $\$ 120,742$. The following formula was used to calculate the ROI (see Equation 3):

$$
R O I(\%)=\frac{\$ 120,742-\$ 143,287}{\$ 143,287} \times 100=-15.73 \%
$$

The results show the organization lost roughly 16 cents for each dollar invested in conducting RPIWs at Site 1, after accounting for the costs of the RPIWs.

At Site 2, there were 4,607 surgeries performed in the preintervention period as compared to 4,548 surgeries during the intervention period, a decrease of 59 surgeries performed in the intervention period. With an average cost per case of $\$ 1,034$ at Site 2 , there was a net loss of $\$ 61,006$.

Overtime increased from 722 hours in the pre-intervention period to 892 hours in the intervention period, which was an increase of 170 hours with a net loss of $\$ 7,975$. Sick time decreased from 1,441 hours in the pre-intervention period to 636 hours in the intervention period, for a cost savings of $\$ 34,263$.

To calculate the ROI, the costs of conducting the six RPIWs at Site $2(\$ 146,954)$ is compared to the cost savings realized $(-\$ 34,718)$. Thus, the ROI for Site 2 is as follows (see Equation 4):

$$
R O I(\%)=\frac{-\$ 34,718-\$ 146,954}{\$ 146,954} \times 100=-123.63 \%
$$

At Site 2, the organization lost about $\$ 1.24$ for each dollar invested in conducting RPIWs.

To explore whether the RPIWs may have produced an impact over a prolonged period of time, data from the preintervention period was compared to the post-intervention period. The lower portion of Table 1 displays the data used to conduct the ROI analysis between the pre-intervention and post-intervention period for both sites. For Site 1, the cost savings observed across the three process measures was $-\$ 235,871$. When compared to the costs of conducting the six RPIWs, the ROI becomes (see Equation 5):

$$
R O I(\%)=\frac{-\$ 235,871-\$ 143,287}{\$ 143,287} \times 100=-264.61 \%
$$

That is, the organization lost about $\$ 2.64$ for each dollar invested in conducting the RPIWs, when the ROI is calculated between the pre-intervention and post-intervention periods.

For Site 2, the cost savings observed across the three process measures was $\$ 72,356$. The costs of conducting the six RPIWs at Site 2 is the same as above $(\$ 146,954)$. Thus, when pre-intervention period data is compared to the postintervention period, the ROI becomes (see Equation 6):

$$
R O I(\%)=\frac{\$ 72,356-\$ 146,954}{\$ 146,954} \times 100=-50.76 \%
$$

In other words, the organization lost approximately 50 cents for each dollar invested in conducting RPIWs at Site 2, after accounting for the costs of the RPIWs.

\subsection{Results of statistical analyses: ITS results}

We report here the results of ITS analyses where there were apparent improvements in the process measures at the intervention sites as indicated in Table 1 . Since all three process measures (surgical volumes, overtime hours, sick time hours) showed improvement at Site 1, we report the corresponding estimates in the three panels of Table 2, and present the related ITS charts for these measures in Figures 1 to 3.

Our results in panel (a) of Table 2 reveal a small drop (-3.09) in the level of surgeries and a small increase (0.005) in the slope of the trend line during the intervention period. Also, a smaller drop (-1.71) in the level of surgeries is observed in the post-intervention period along with a very small flattening of the trend slope. None of these interruptions are statistically significant ( $\mathrm{p}$-values are much higher than $5 \%$ ). As for the pattern of end-of-shift overtime hours at Site 1, no statistically significant change in either the level or the slope of the trend line for overtime hours is observed in the intervention period [see panel (b) of Table 2]. Notwithstanding, a statistically significant drop in the level along with a rise in the slope of the trend in overtime hours occurs during the post-intervention period as reported in panel (b) of Table 2. Also, our results show no statistically significant interruptions in the pattern of sick time hours during the intervention and post-intervention periods [see panel (c) of Table 2]. 
Table 2. Estimation results for patterns of process measures at Site 1

\begin{tabular}{|c|c|c|c|}
\hline Parameter & $\begin{array}{c}\text { Panel (a) } \\
\text { Surgical volumes }\end{array}$ & $\begin{array}{c}\text { Panel (b) } \\
\text { Overtime hours }\end{array}$ & $\begin{array}{c}\text { Panel (c) } \\
\text { Sick time hours }\end{array}$ \\
\hline & Estimate ( $p$-value) & Estimate ( $p$-value) & Estimate ( $p$-value) \\
\hline$C$ (common level) & $40.16(.000)$ & $15.99(.000)$ & $42.46(.000)$ \\
\hline$B$ (common slope) & $0.005(.432)$ & $-0.002(.826)$ & $-0.020(.161)$ \\
\hline$C_{l}$ (level change) & $-3.09(.217)$ & $1.14(.734)$ & $0.643(.912)$ \\
\hline$B_{I}$ (slope change) & $0.005(.519)$ & $-0.006(.570)$ & $0.004(.832)$ \\
\hline$C_{2}$ (level change) & $-1.71(.666)$ & $-36.56(.000)$ & $3.03(.741)$ \\
\hline$B_{2}$ (slope change) & $-0.002(.811)$ & $0.057(.000)$ & $0.013(.522)$ \\
\hline$R^{2}$ & 0.007 & 0.067 & 0.014 \\
\hline$F$-statistic & $1.10(.360)$ & $10.46(.000)$ & $2.19(.053)$ \\
\hline Number of observations & 744 & 731 & 744 \\
\hline
\end{tabular}

Note. $C_{l}$ and $B_{l}$ refer to the intervention period; $C_{2}$ and $B_{2}$ refer to the post-intervention period.

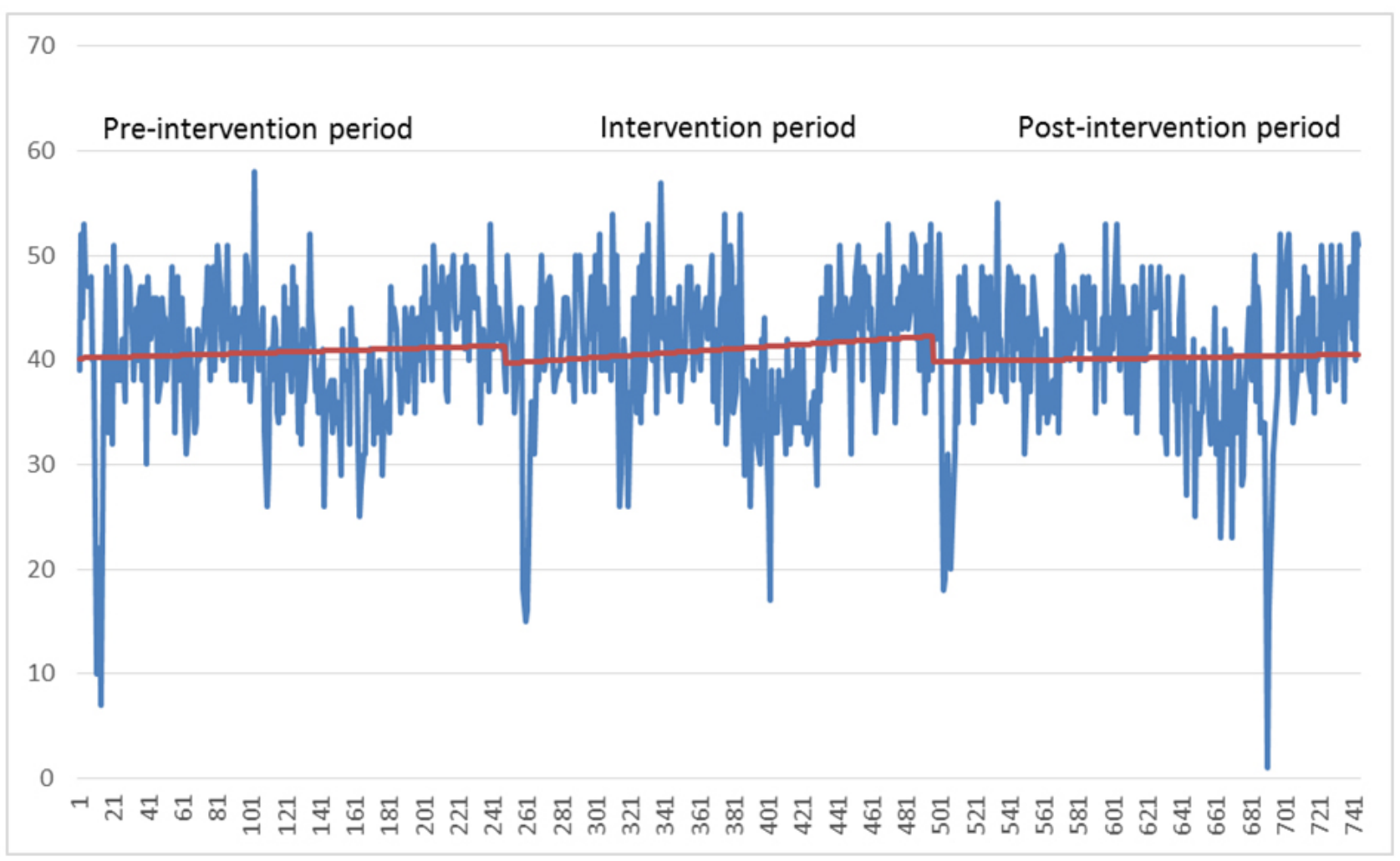

Figure 1. The patterns of surgical volumes at Site 1 over the three periods 
70.00

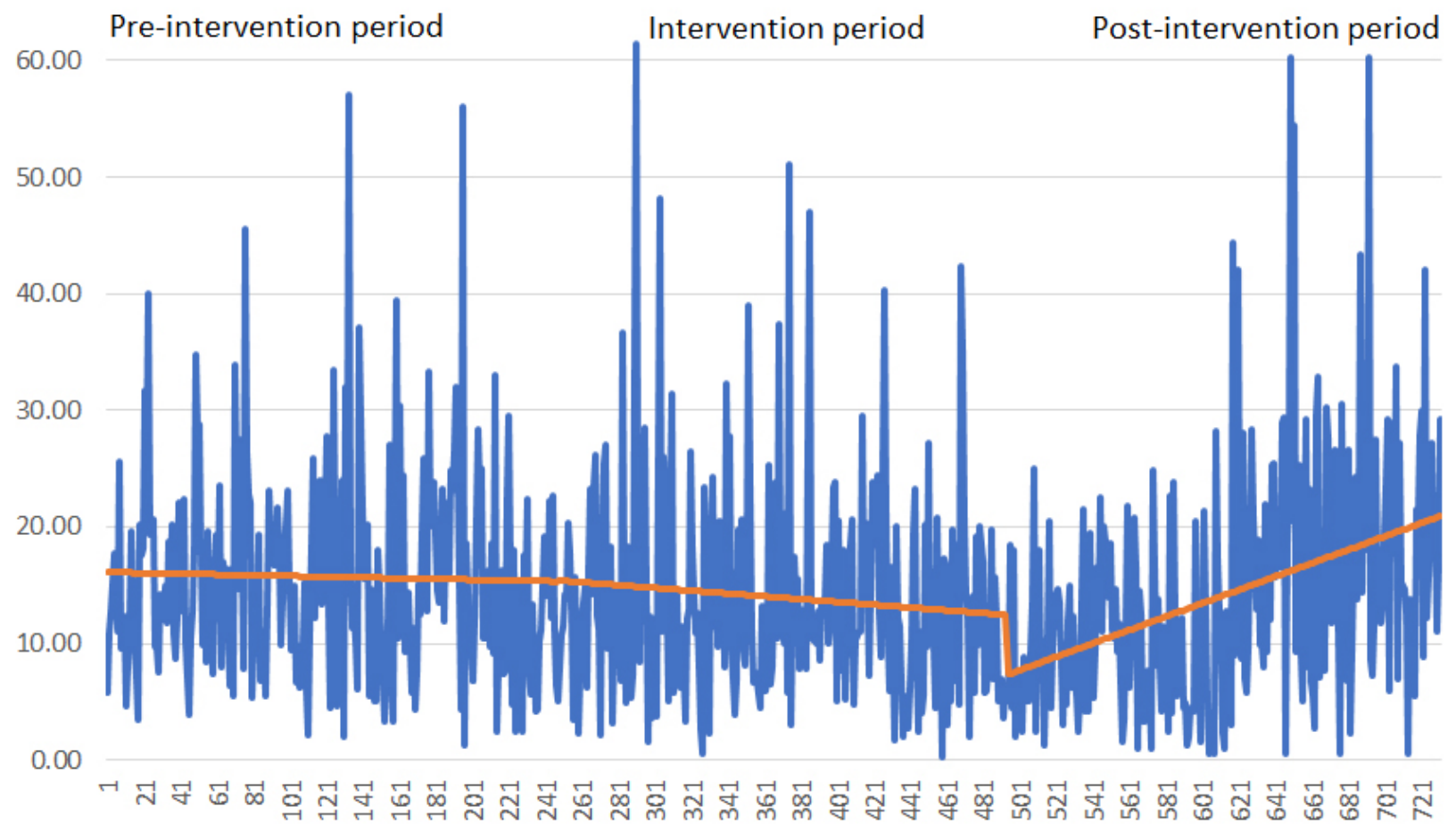

Figure 2. The patterns of overtime hours at Site 1 over the three periods

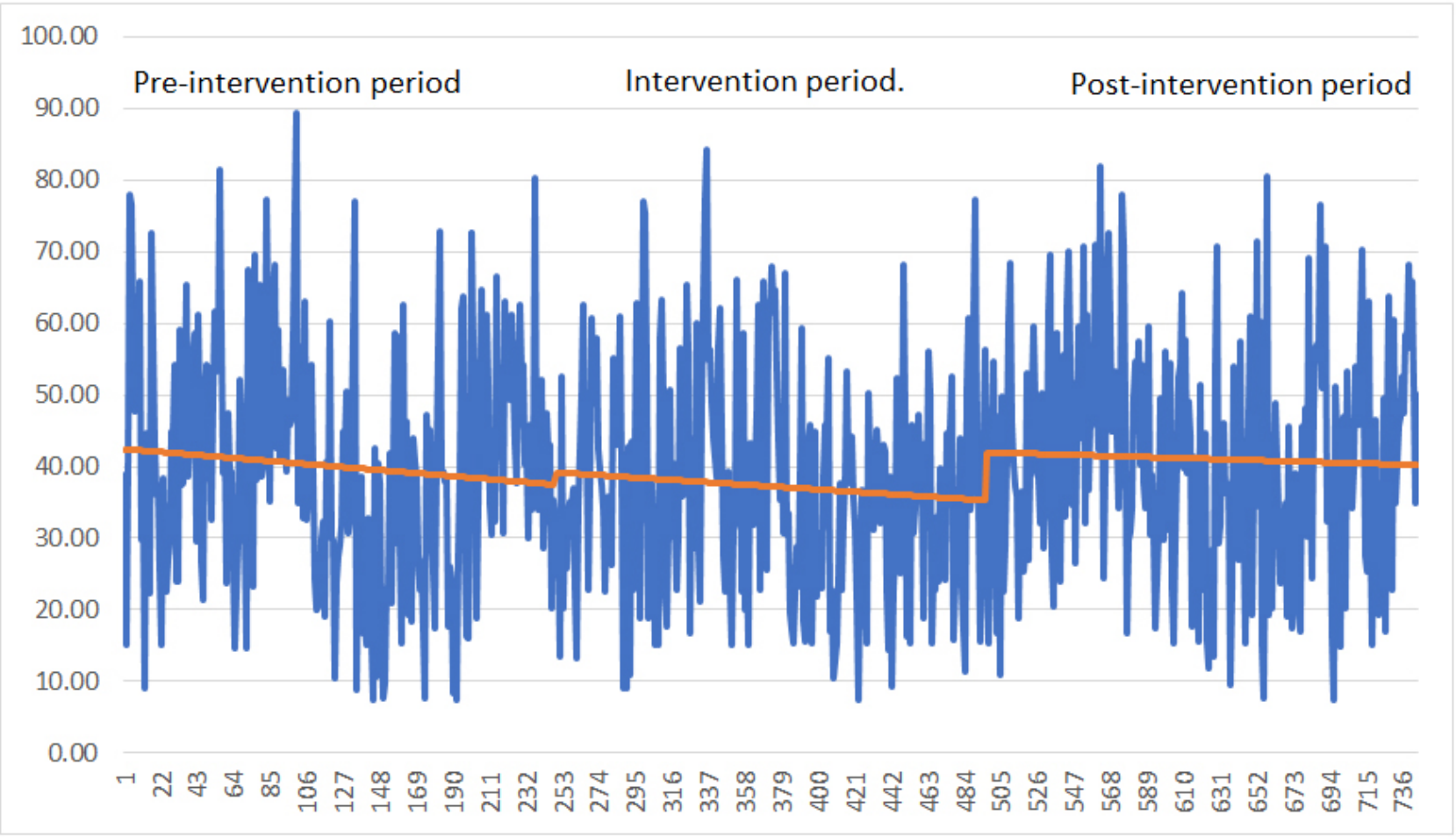

Figure 3. The patterns of sick time hours at Site 1 over the three periods 
To compare the process measures at the intervention Site 1 with its control site (Site 3), ITS analyses were applied to the differences in these metrics between Site 1 and Site 3 . The patterns of the differences in process measures turned out to be similar to those observed at Site 1. We report the estimation results for these differences in Table 3.

As seen in panels (a) and (c) of Table 3, there are hardly any interruptions in either the levels or the slopes of the trends of differences in the surgical volumes and sick time hours between Site 1 and Site 3 during both the intervention and post-intervention periods, as none of the changes are statistically significant (see also Figure 4). However, statistically significant interruptions occur for the overtime hours in the post-intervention period. More specifically, we observe a sizable decline in the level and a sizable increase in the slope of the overtime trends [see panel (b) of Table 3].

Table 3. Estimation results for patterns of differences in process measures (Site 1 vs. Site 3 )

\begin{tabular}{lccc}
\hline \multirow{2}{*}{ Parameter } & $\begin{array}{c}\text { Panel (a) } \\
\text { Difference in surgical volumes }\end{array}$ & $\begin{array}{c}\text { Panel }(\mathbf{b}) \\
\text { Difference in overtime hours }\end{array}$ & $\begin{array}{c}\text { Panel (c) } \\
\text { Difference in sick time hours }\end{array}$ \\
\cline { 2 - 4 } & Estimate $(\boldsymbol{p}$-value) & Estimate $(\boldsymbol{p}$-value $)$ & Estimate $(\boldsymbol{p}$-value) \\
\hline$C$ (common level) & $10.00(.000)$ & $12.15(.000)$ & $21.09(.000)$ \\
$B$ (common slope) & $-0.001(.912)$ & $-0.007(.459)$ & $-0.008(.636)$ \\
$C_{l}$ (level change) & $2.33(.382)$ & $2.15(.592)$ & $-9.04(.205)$ \\
$B_{1}$ (slope change) & $-0.008(.372)$ & $-0.008(.549)$ & $0.020(.420)$ \\
$C_{2}$ (level change) & $0.74(.861)$ & $-37.32(.000)$ & $0.577(.958)$ \\
$B_{2}$ (slope change) & $-0.003(.698)$ & $0.058(.000)$ & $0.004(.849)$ \\
$R^{2}$ & 0.013 & 0.073 & 0.007 \\
$F$-statistic & $2.01(.074)$ & $10.59(.000)$ & $1.12(.344)$ \\
Number of observations & 744 & 675 & 742 \\
\hline
\end{tabular}

Note. $C_{l}$ and $B_{l}$ refer to the intervention period; $C_{2}$ and $B_{2}$ refer to the post-intervention period.

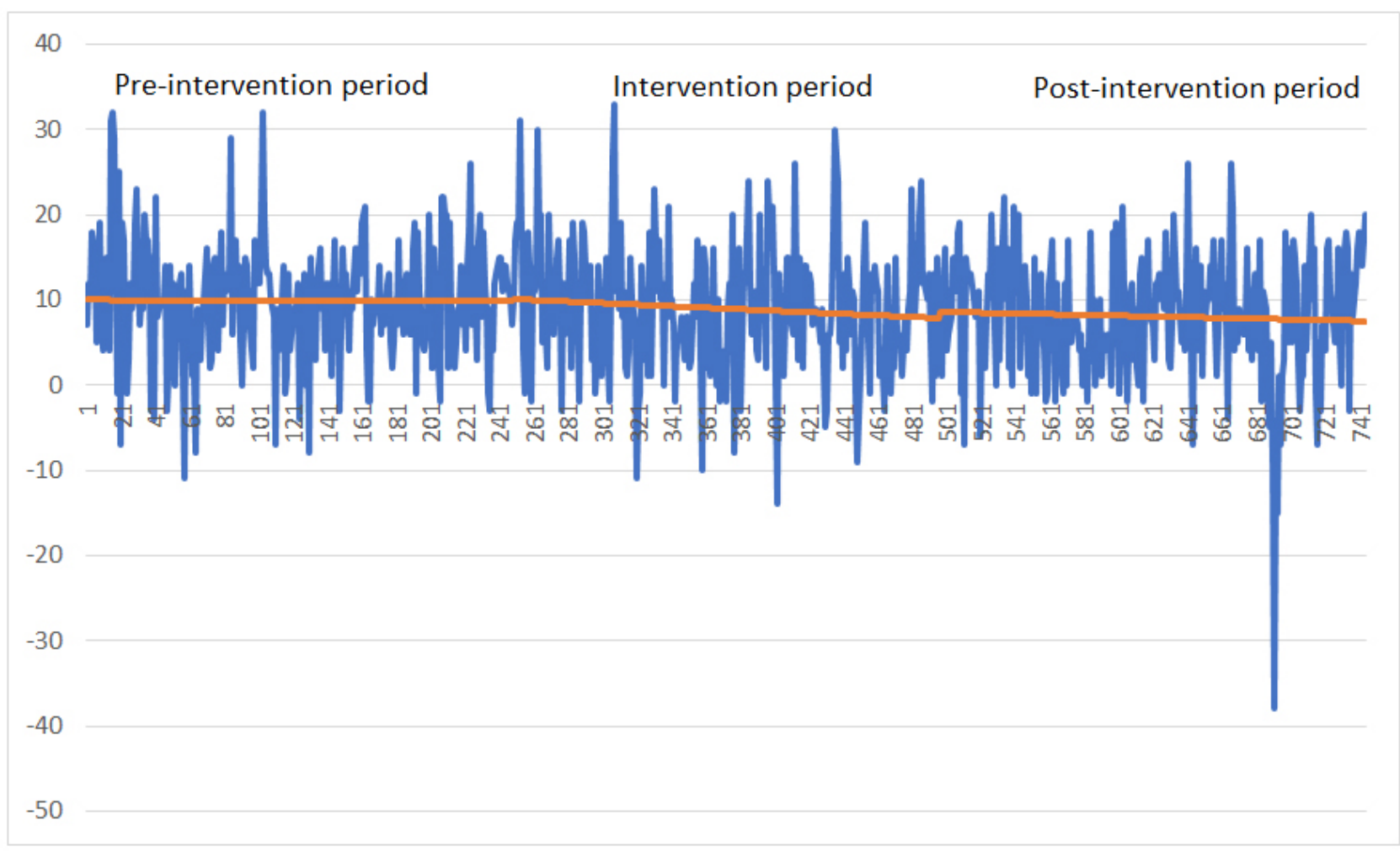

Figure 4. The patterns of difference in surgical volumes (Site 1 vs. Site 3) 


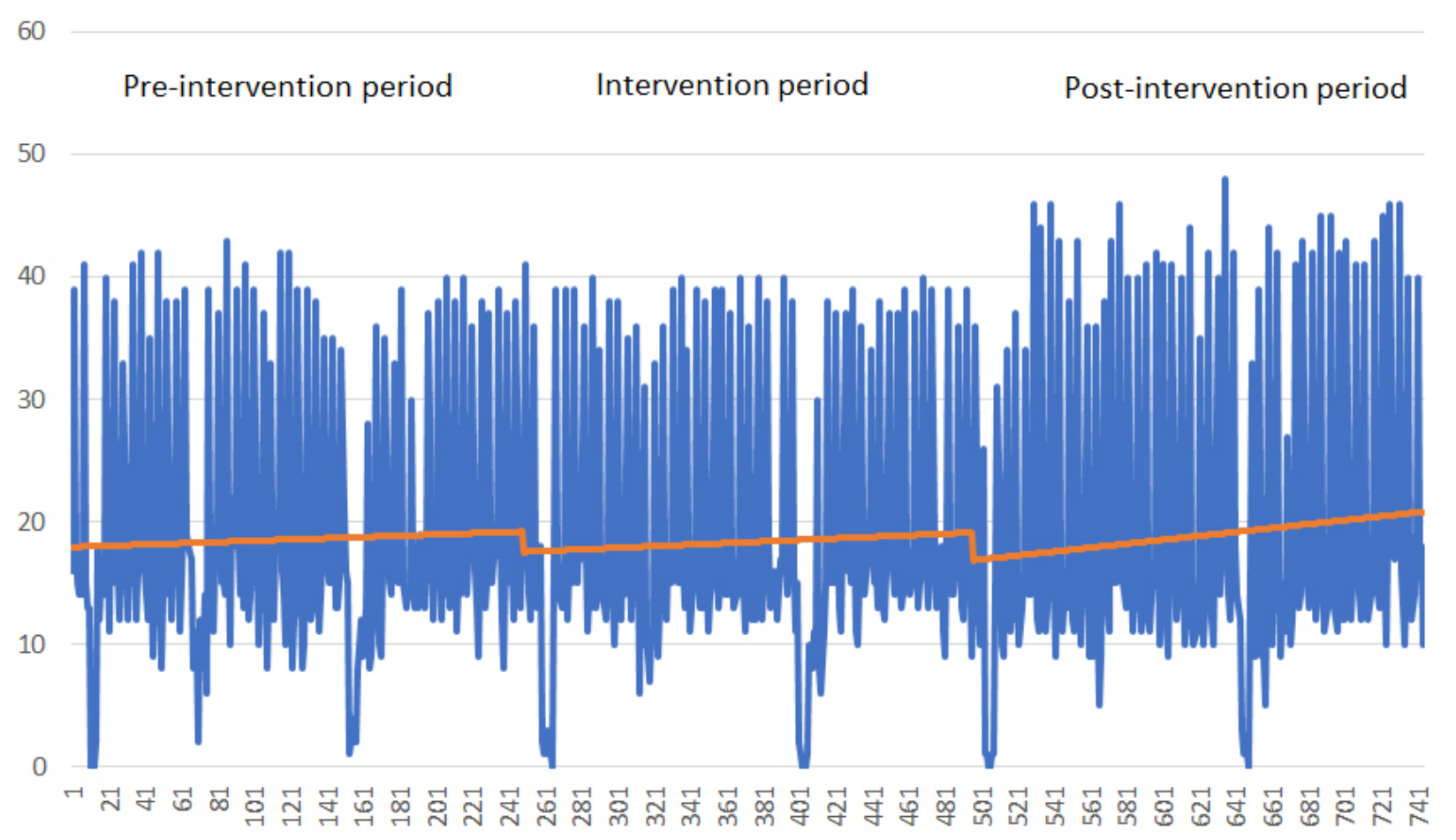

Figure 5. The patterns of surgical volumes at Site 2 over the three periods

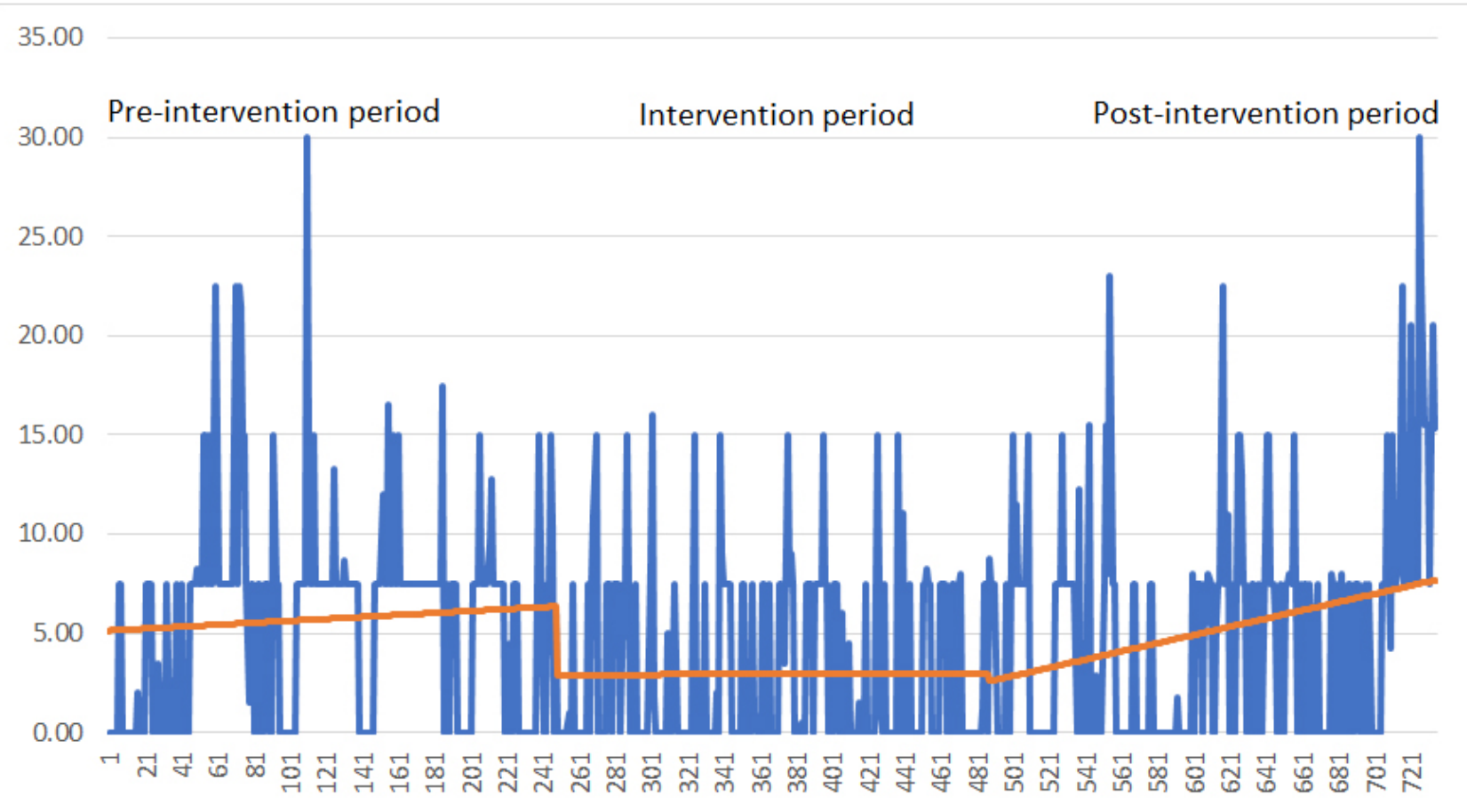

Figure 6. The patterns of sick time hours at Site 2 over the three periods 
At the other intervention site (Site 2), surgical volumes and sick time hours improved, but not overtime hours. For brevity, we do not report the estimation results here. We found no statistically significant interruptions in the levels or slopes of the trends of surgical volumes at this site as a result of the RPIW interventions for both the intervention and postintervention periods (see Figure 5). As for the sick time hours, no statistically significant interruptions were observed during the intervention period. However, the interruptions in both the level and slope of the time trend for sick time hours were relatively large in magnitude and statistically significant in the post-intervention period. During this period, the level dropped by 12.81 , and the slope rose by 0.015 . In other words, we observe some off-setting interruptions in the post-intervention period (see Figure 6).

We compared the patterns of surgeries and sick time hours between Site 2 and its control site (Site 4), by applying the ITS analysis to the differences in these measures between the two sites. Our results revealed no significant interruptions in the patterns of differences in surgical volumes between the two sites in the intervention or post-intervention period. The patterns of differences in sick time hours between the two sites are somewhat similar to those found for sick time hours at Site 2. More specifically, we observe a sizable drop in the level, but a moderate increase in the slope of the trend only in the post-intervention period. Both of these changes are statistically significant. The related estimations and charts are available from the authors.

\section{Discussion}

The lack of reliable data associated with each particular RPIW, coupled with the observation that individual RPIWs did not produce a sustainable impact on the overall operation of the entire surgical department, led us to direct our analysis towards the cumulative effects of all RPIWs within each site. This is consistent with previous research, which found that efforts to improve individual components of the surgical process are unlikely to have substantive or sustainable impact. ${ }^{[38]}$

The ROI rates calculated for the cumulative effects of the six separate RPIWs at each of the two sites were found to be negative, which not only implies that there was no return on investment from the RPIWs but also part of the investment (as in Site 1 in the intervention period, and Site 2 in the post-intervention period), or even more than the entire investment (as in Site 2 in the intervention period and Site 1 in the post-intervention) was lost. Thus, we did not find any quantitative evidence to claim that the outcomes justify the investments.

Published by Sciedu Press
In terms of the statistical results, the patterns of process measures including the number of daily surgeries, overtime hours and sick time hours as depicted in various ITS graphs indicate a high degree of volatility in these metrics with no apparent trends. Such daily volatility is to be expected as the need for surgeries and end of shift overtime hours are unpredictable. So is the occurrence of sick time hours among the medical staff. This study aimed to find out if there are any systematic changes or interruption in the patterns of process measures as a result of the RPIW interventions, either in the intervention period or in the post-intervention period. As stated previously, we chose to focus on the measures that appeared to have improved after the intervention as reported in Table 1. Since all three process measures of surgical volumes, overtime, and sick time hours showed improvement at Site 1 , we examined the potential interruptions in the patterns of these measures at that site. We found no statistically significant interruption in either the levels or the slopes for the trends in surgical volumes and sick time hours as reported in panels (a) and (c) of Table 2. But we did find statistically significant changes in both the level and slope of the trend for overtime hours only in the post-intervention period as reported in panel (b) of Table 2. Nevertheless, the reduction in the level of overtime hours were offset with the rising slope of the hours trend, so much so that towards the end of the post-intervention period the overtime hours stood higher than the level before the intervention began (see Figures 1 to 3).

In order to check whether the patterns of the process measures at Site 1 differed from those at the control site (Site 3 ), we examined the potential interruptions in the performance differences between the two sites. Consistent with our previous results, we did not find any statistically significant interruptions in the patterns of differences in surgical volumes and sick time hours for the two sites, but we did find a significant drop in the level and a rise in the slope of the difference trend for overtime hours in the post-intervention period as reported in Table 3. Here too, the rise in the slope offset the drop in the level, effectively bringing the overtime levels back to the pre-intervention level (see Figure 4).

We found similar results for the second intervention site (Site 2 ), where both the surgical volumes and sick time hours showed improvement. Our statistical results (not reported here) indicate no significant interruptions in the daily surgical volumes in either the intervention or the post-intervention period (see Figure 5). That is, the RPIWs do not appear to have improved the surgical volumes at this site. For sick time hours, our results do show statistically significant interruptions (a drop in the level but a rise in the slope) for the post-intervention period (see Figure 6). However, such 
off-setting interruptions have the net effect of increasing the level of sick time hours at the end of the post-intervention period above the level at the beginning of the pre-intervention period-once again, showing no evidence of sustained improvement as a result of the RPIW interventions.

The ITS results comparing Site 2 with its control site (Site 4 ) echo the previous results. There are no statistically significant interruptions in the differences in surgical volumes between the two sites. Statistically significant drops in the level of sick time hours both in the intervention and postintervention periods were offset by the rising slope of the trend bringing the levels almost back to that in the preintervention period.

Taken together, our empirical results indicate that the investment in RPIWs at two surgical sites in British Columbia have had no positive monetary returns. Moreover, any apparent improvement in productivity or cost saving did not appear to be systematic or sustained over the intervention and post-intervention periods.

\section{Conclusions}

In the final analysis, proving value for money is much more difficult in the complex environment that is healthcare as compared to manufacturing, where Lean emerged. As such, our results challenge unsubstantiated claims of significant financial benefits from Lean activities or similar quality improvement interventions.

There are a number of limitations that should be considered with regard to this study. First, lack of reliable data prevented a full economic evaluation a la Drummond et al. ${ }^{[26]}$ Therefore, our approach was a form of partial evaluation.
Second, since the RPIWs were not the only interventions at the two sites, we cannot rule out the potential confounding effects of other factors on the process measures. Accordingly, we cannot claim a causal relationship between RPIWs and performance outcomes. Third, although an attempt was made to match the intervention sites with non-intervention control sites, this matching could not completely prevent any systematic bias, as there could be characteristics unique to each site, such as other improvement activity that may have impacted individual performance. Fourth, since it was not feasible to analyze the surgeries by type or other patient-level characteristics, this study is limited to a general analysis of surgical performance.

While we acknowledge these limitations, we believe this study makes a genuine contribution to the empirical literature on Lean-related interventions in healthcare, and surgical service units, in particular. Owing to the amount of effort it takes organizations to become competent at simply measuring results at a basic level as opposed to achieving advanced proficiency, perhaps it would be more prudent for healthcare leaders to invest resources in encouraging organizations to reach a basic or higher level of proficiency in measurement. Not only would such an approach help to circumvent waste produced by unsuccessful improvement projects, it could also promote the building blocks of large-scale change.

\section{Disclosure}

This research received no specific grant from any funding agency in the public, commercial, or not-for-profit sectors.

\section{CONFlicts OF InTEREST Disclosure}

The authors declare they have no conflicts of interest.

\section{REFERENCES}

[1] Motwani J. A business process change framework for examining lean manufacturing: A case study. Ind Manage Data Syst. 2003; 103(5): 339-346. https://doi .org/10.1108/02635570310477398

[2] Black J. Transforming the patient care environment with lean six sigma and realistic evaluation. J Healthc Qual. 2009; 31(3): 2935. PMid: 19522345. https ://doi.org/10.1111/j.1945-147 4.2009.00028.x

[3] Shortell SM, Blodgett JC, Rundall TG, et al. Use of lean and related transformational performance improvement systems in hospitals in the United States: Results from a national survey. Jt Comm J Qual Patient Saf. 2018; 44(10): 574-582. PMid: 30243359. https://doi.org/10.1016/j.jcjq.2018.03.002

[4] Brandao de Souza L. Trends and approaches in lean healthcare. Leadersh Health Serv. 2009; 22(2): 121-139. https ://doi .org/10.1 $108 / 17511870910953788$

[5] Mazzocato P, Savage C, Brommels M, et al. Lean thinking in health- care: A realist review of the literature. BMJ Qual Saf. 2010; 19(5): 376-382. PMid: 20724397. https://doi.org/10.1136/qshc. 2 009.037986

[6] DelliFraine JL, Langabeer JR, Nembhard IM. Assessing the evidence of six sigma and lean in the healthcare industry. Qual Manag Health Care. 2010; 19(3): 211-225. PMid: 20588140. https: //doi.org/10.1097/QMH.0b013e3181eb140e

[7] Al-Baushi S, Sohal AS, Singh PJ, et al. Readiness factors for lean implementation in healthcare settings - a literature review. J Health Organ Manag. 2014; 28(2): 135-153. PMid: 25065107. https://doi.org/10.1108/JHOM-04-2013-0083

[8] Parker SK. Longitudinal effects of lean production on employee outcomes and the mediating role of work characteristics. J Appl Psychol. 2003; 88(4): 620-634. PMid: 12940403. https://doi.org/10.1 037/0021-9010.88.4.620

[9] Pettersen J. Defining lean production: Some conceptual and practical issues. The TQM Journal. 2009; 21(2): 127-142. https: 
//doi.org/10.1108/17542730910938137

[10] D'Andreamatteo A, Ianni L, Lega F. Lean in healthcare: A comprehensive review. Health Policy. 2015; 119(9): 1197-1209. PMid: 25737260. https://doi.org/10.1016/j.healthpol.2015.0 2.002

[11] Rotter T, Plishka CT, Adegboyega L, et al. What is lean management in health care? Development of an operational definition for a Cochrane Systematic Review. Eval Health Prof. 2018; 1-25.

[12] Naik T, Duroseau Y, Zehtabchi S, et al. A structured approach to transforming a large public hospital emergency department via lean methodologies. J Healthc Qual. 2012; 34(2): 86-97. PMid: 22188582. https ://doi.org/10.1111/j.1945-1474.2011.00181.x

[13] Wolf L, Costantinou E, Limbaugh C, et al. Fall prevention for inpatient oncology using lean and rapid improvement event techniques. HERD. 2013; 7(1): 85-101. PMid: 24554318. https: //doi.org/10.1177/193758671300700108

[14] Nicholas J. An integrated lean-methods approach to hospital facilities redesign. Hosp Top. 2012; 90(2): 47-55. PMid: 22671435. https://doi.org/10.1080/00185868.2012.679911

[15] Nelson-Peterson DL, Leppa CJ. Creating an environment for caring using lean principles of the Virginia Mason Production System. J Nurs Admin. 2007; 37(6): 287-294. PMid: 17563521. https://doi.org/10.1097/01. NNA.0000277717.34134.a9

[16] Ovretveit J. Does improving quality save money? A review of evidence of which improvements to quality reduce costs to health service providers. London: The Health Foundation; 2009.

[17] Ulhassan W, Sandahl C, Westerlund H, et al. Antecedents and characteristics of lean thinking implementation in a Swedish hospital: A case study. Qual Manag Health. 2013; 22(1): 48-61. PMid: 23271593. https://doi.org/10.1097/QMH.0b013e31827dec5a

[18] Iannettoni MD, Lynch WR, Parekh KR, et al. Kaizen method for esophagectomy patients: Improved quality control, outcomes, and decreased costs. Ann Thorac Surg. 2011; 91(4): 1011-1018. PMid: 21292238. https://doi.org/10.1016/j.athoracsur .2011 .01 .001

[19] Collar RM, Shuman AG, Feiner S, et al. Lean management in academic surgery. J Am Coll Surg. 2012; 214(6): 928-936. PMid: 22626546. https://doi.org/10.1016/j.jamcollsurg. 2012 .03 .002

[20] Warner CJ, Walsh DB, Horvath AJ, et al. Lean principles optimize on-time vascular surgery operating room starts and decrease resident work hours. J Vasc Surg. 2013; 58(5): 1417-1422. PMid: 23827339. https://doi.org/10.1016/j.jvs.2013.05.007

[21] Schwarz P, Pannes KD, Nathan M, et al. Lean processes for optimizing OR capacity utilization: Prospective analysis before and after implementation of value stream mapping (VSM). Langenbecks Arch Surg. 2011; 396(7): 1047-1053. PMid: 21826521. https ://doi.org/10.1007/s00423-011-0833-4

[22] Montella E, Di Cicco MV, Ferraro A, et al. The application of lean six sigma methodology to reduce the risk of healthcare-associated infections in surgery departments. J Eval Clin Pract. 2017; 23: 530-539. PMid: 27860065. https://doi.org/10.1111/jep. 12662

[23] Improta G, Balato G, Romano $M$, et al. Lean six sigma: a new approach to the management of patients undergoing prosthetic hip replacement surgery. J Eval Clin Pract. 2015; 662-672. PMid: 25958776. https://doi.org/10.1111/jep.12361

[24] Gayed B, Black S, Daggy J, et al. Redesigning a joint replacement program using lean six sigma in a Veterans Affairs hospi- tal. JAMA Surg. 2013; 148(11): 1050-1056. PMid: 24026166 https://doi.org/10.1001/jamasurg.2013.3598

[25] Canadian Institutes of Health Research, Natural Sciences and Engineering Research Council of Canada, \& Social Sciences and Humanities Research Council of Canada. Tri-Council policy statement: Ethical conduct for research involving humans. December 2010. Available from: http://www.pre.ethics.gc.ca/pdf/eng/tcp s2/TCPS_2_FINAL_Web.pdf

[26] Drummond MF, Sculpher MJ, Torrance GW, et al. Methods for the economic evaluation of health care programmes. 3rd ed. Oxford: Oxford University Press; 2005.

[27] Sari N, Rotter T, Goodridge D, et al. An economic analysis of a system wide lean approach: Cost estimations for the implementation of lean in the Saskatchewan healthcare system for 2012 2014. BMC Health Serv Res. 2017; 17: 523. PMid: 28774301. https://doi .org/10.1186/s12913-017-2477-8

[28] Howard KB, Pathak DS. Determining the difference among cost savings, cost avoidance, and cost reduction. Pharm Pract Manag Q. 1999; 19(3): 1-7.

[29] Moraros J, Lemstra M, Nwankwo C. Lean interventions in healthcare: Do they actually work? A systematic literature review. Int J Qual Health Care. 2016; 28(2): 150-165. PMid: 26811118. https://doi.org/10.1093/intqhc/mzv123

[30] Kaplan T, Boyer M. Leading cost reductions in healthcare. In: Wellman J, Hagan P, Jeffries H, eds, Leading the Lean Healthcare Journey: Driving Culture Change to Increase Value. New York, NY: Productivity Press; 2011. 235-246 p. PMid: 20173741. https ://doi.org/10.1201/b10396-21

[31] MacKenzie J, Hall W. Current State of Lean in Canadian Healthcare Ottawa, ON: The Conference Board of Canada; 2014.

[32] Lowe G. How employee engagement matters for hospital performance. Healthc Q. 2012; 15(2): 29-39. PMid: 22688203. https : //doi.org/10.12927/hcq.2012.22915

[33] Bernal JL, Cummins S, Gasparrini A. Interrupted time series regression for the evaluation of public health interventions: A tutorial. Int $\mathbf{J}$ Epidemiol. 2016; 46(1): 348-355.

[34] Cruz M, Bender M, Ombao H. A robust interrupted time series model for analyzing complex healthcare intervention data. Stat Med. 2017; 36(29): 4660-4676. PMid: 28850683. https ://doi.org/10.100 $2 / \operatorname{sim} .7443$

[35] Fretheim A, Tomic O. Statistical process control and interrupted time series: A golden opportunity for impact evaluation in quality improvement. BMJ Qual Saf. 2015; 24: 748-752. PMid: 26316541. https ://doi.org/10.1136/bmjqs-2014-003756

[36] Kontopantelis E, Doran T, Springate DA, et al. Regression based quasi-experimental approach when randomization is not an option: Interrupted time series analysis. BMJ. 2015; 350: h2750. PMid: 26058820. https://doi.org/10.1136/bmj.h2750

[37] Penfold RB, Zhang F. Use of interrupted time series analysis in evaluating health care quality improvements. Acad Pediatr. 2013; $13(6$ Suppl): S38-44. PMid: 24268083. https://doi.org/10.1016/ j.acap. 2013.08.002

[38] Cima RR, Brown MJ, Hebl JR, et al. Use of lean and six sigma methodology to improve operating room efficiency in a high-volume tertiary-care academic medical center. J Am Coll Surg. 2011; 213(1): 83-92. PMid: 21420879. https://doi.org/10.1016/j.jamcol lsurg. 2011.02.009 PMid:21420879 